\title{
SHELL CONTINUUM MODEL OF FREE NONLINEAR VIBRATIONS OF CARBON NANOTUBES WITH CONSIDERATION FOR NONLOCAL ELASTICITY
}

\author{
A. Pidgorny Institute of Mechanical Engineering Problems, \\ 2/10 Pozharsky St., Kharkiv, 61046, Ukraine; e-mail:avramov@nas.gov.ua
}

In this paper, a model of nonlinear vibrations of a carbon nanotube based on the shell theory is presented. On the basis of variational principles, a system of three nonlinear partial differential equations in three projections of middle surface point displacements was derived. In doing so, use was made of the geometrically nonlinear Sanders-Koiter shell theory and nonlocal elasticity, which modifies the form of Hooke's law. It was assumed that conjugate vibrational modes are involved in shell vibrations under nonlinear deformation. This assumption together with the Galerkin approach made it possible to derive a nonlinear system of ordinary differential equations in generalized coordinates of the structure, which describes free nonlinear vibrations of the nanotube. The dynamic system obtained contains quadratic and cubic nonlinear terms. To calculate the free nonlinear vibrations, use was made of the harmonic balance method, in which vibrations are represented as a Fourier series. Using this method, the backbone curves of the free nonlinear vibrations were calculated. The backbone curves proved to be soft. The stability of the periodic vibrations obtained was analyzed by direct numerical integration of the motion equations. It was shown that free nonlinear vibrations of carbon nanotubes lose stability due to the Naimark-Saker bifurcation, and almost periodic vibrations are set up due to this bifurcation. These almost periodic motions were studied using Poincare sections. The Poincare section calculations showed that an invariant torus is formed in the system. The calculated almost periodic vibrations are shown in bifurcational diagrams. The longitudinal vibrations and the flexural motions have comparable amplitudes. These properties of nanotubes are new.

Keywords: Sanders-Koiter theory, nonlocal elasticity, nanotube shell model, Naimark-Saker bifurcation.

1. Gibson R. F., Ayorinde E. O., Wen Y.-F. Vibrations of carbon nanotubes and their composites: A review. Composites Science and Technology. 2007. No. 67. Pp. 1-28.

2. Sirtori C. Applied physics: bridge for the terahertz gap. Nature. 2002. No. 417. Pp. 132-133.

3. Jeon T., Kim K. Terahertz conductivity of anisotropic single walled carbon nanotube films. Applied Physics Letters. 2002. No. 80. Pp. 3403-3405.

4. Yoon J., Ru C. Q., Mioduchowski A. Sound wave propagation in multiwall carbon nanotubes. Journal of Applied Physics. 2003. No. 93. Pp. 4801-4806.

5. Iijima S., Brabec C., Maiti A., Bernholc J. Structural flexibility of carbon nanotubes. Journal of Chemical Physics. 1996. No. 104. Pp. 2089-2092.

6. Yakobson B. I., Campbell M. P., Brabec C. J., Bernholc J. High strain rate fracture and C-chain unraveling in carbon nanotubes. Computer Material Science. 1997. No. 8. Pp. 241-248.

7. Wang C. Y., Zhang L. C. An elastic shell model for characterizing single-walled carbon nanotubes. Nanotechnology. 2008. No. 19. 195704.

8. Wang Q., V. K. Varadan Application of nonlocal elastic shell theory in wave propagation analysis of carbon nanotubes. Smart Material Structure. 2007. No. 16. Pp. 178-190.

9. Fu Y. M., Hong J. W., Wang X. $Q$. Analysis of nonlinear vibration for embedded carbon nanotubes. Journal of Sound and Vibration. 2006. No. 296. Pp. 746-756.

10. Ansari R., Hemmatnezhad M. Nonlinear vibrations of embedded multi-walled carbon nanotubes using a variational approach. Mathematical and Computer Modeling. 2011. No. 53. Pp. 927-938.

11. Ansari R., Hemmatnezhad M. Nonlinear finite element analysis for vibrations of double-walled carbon nanotubes. Nonlinear Dynamics. 2012. No. 67. Pp. 373-383.

12. Hajnayeb A., Khadem S. E. Analysis of nonlinear vibrations of double-walled carbon nanotubes conveying fluid. Journal of Sound and Vibration. 2012. No. 331. Pp. 2443-2456.

13. Avramov K. V., Mikhlin Yu. B. Nonlinear Theory of Elastic Systems. V.1. Approaches, Methods, and Phenomena (in Russian). Moscow: Institut Komyuternykh Issledovaniy. 2015. 716 pp.

14. Amabili M. Nonlinear vibrations and stability of shells and plates. Cambridge: Cambridge University Press. 2008. 605 pp.

15. Hu Y.-G., Liew K. M., Wang Q., He X. Q., Yakobson B. I. Nonlocal shell model for elastic wave propagation in single- and double-walled carbon nanotubes. Journal of the Mechanics and Physics of Solids. 2008. No. 56. Pp. 34753485 .

16. Peddieson J., Buchanan G. R., McNitt R. P. Application of nonlocal continuum models to nanotechnology. International Journal of Engineering Science. 2003. No. 41. Pp. 305-312.

Received 21.02.2018, in final form 17.05.2018 
